\title{
High-Throughput RNA Sequencing Reveals the Effect of NB-UVB Phototherapy on Major Inflammatory Molecules of Lesional Psoriasis
}

\author{
Pinyadapat Vacharanukrauh' \\ Jitlada Meephansan (1D' \\ Pattarin Tangtanatakul ${ }^{2}$ \\ Wipasiri Soonthornchai ${ }^{3}$ \\ Jongkonnee Wongpiyabovorn ${ }^{4}$ \\ Onsiri Serirat ${ }^{5}$ \\ Mayumi Komine ${ }^{6}$
}

'Division of Dermatology, Chulabhorn International College of Medicine, Thammasat University, Pathum Thani, 12120, Thailand; ${ }^{2}$ Department of Transfusion Medicine and Clinical Microbiology, Faculty of Allied Health Sciences, Chulalongkorn University, Bangkok, I0330, Thailand;

${ }^{3}$ Demonstration School, University of Phayao, Phayao, 56000, Thailand; ${ }^{4}$ Division of Immunology, Department of Microbiology, Faculty of Medicine, Center of Excellence in Immunology and Immune Mediated Diseases, Chulalongkorn University, Bangkok, 10330, Thailand; ${ }^{5}$ Division of Dermatology, Department of Medicine, Rajavithi Hospital, Ministry of Public Health, Bangkok, 10400, Thailand; ${ }^{6}$ Department of Dermatology, Jichi Medical University, Tochigi, Japan
Correspondence: Jitlada Meephansan Division of Dermatology, Chulabhorn International College of Medicine, Thammasat University, Rangsit Campus, Klong Luang, Pathum Thani, I2120, Thailand

Tel +662564-4444, ext. 1535

Fax +662564-4440, ext.7594

Email kae_mdcu@yahoo.com
Objective: To identify the narrowband ultraviolet B (NB-UVB)-induced molecular mechanisms that may account for their anti-inflammatory efficacy, gene expression and transcriptome profiling, which were performed using advanced molecular techniques.

Methods: This research was conducted on patients with moderate-to-severe plaque-type psoriasis who received NB-UVB treatment. RNA sequencing (RNA-Seq) was conducted to assay the transcriptomes and identify the differentially expressed transcripts that had been enriched during the major pathway analysis.

Results: Clinical improvement of psoriasis by NB-UVB therapy is linked to the suppression of the "immunological signaling pathways" and "cell cycle regulatory, growth and proliferation pathways" which are critical to the pathogenesis of the disease. In addition, these results were further substantiated by demonstrating that NB-UVB therapy has a significant effect on keratinocyte differentiation and affects the regulation of genes and inflammatory mediators that are related to cell proliferation and apoptosis. Moreover, NB-UVB phototherapy is also involved with the downregulation of toll-like receptors signaling in lesional psoriasis.

Conclusion: NB-UVB is an effective treatment for psoriasis. Our study supports the conclusion that the clinical effectiveness of NB-UVB therapy is based on the suppression of a broad range of inflammatory signaling pathways, gene expression of inflammatory cytokines and increased expressions of anti-inflammatory signaling pathways in psoriatic skin. This is the first study that applied advanced molecular techniques to investigate phototherapy as a new key to unlock genetic knowledge and create novel information. Ultimately, the goal is to increase medical knowledge and improve the patient care of psoriasis.

Keywords: psoriasis, pathogenesis, inflammation, NB-UVB, high-throughput RNAsequencing, Inflammation, gene, translational study, chronic skin disease, UVB irradiation

\section{Introduction}

Psoriasis vulgaris, major chronic immune-mediated skin disease, affects $1-3 \%$ of the adult population worldwide. ${ }^{1}$ Psoriasis is one of the major complex skin diseases that is significantly linked to genetic predisposition, major histocompatibility alleles, and environmental factors. ${ }^{2}$ Over the past few years, the cellular and molecular contributions to psoriasis were further elucidated. Pathways of cytokine and chemokine are directly linked to cellular communication and controlling inflammatory networks in psoriasis. Significantly, the contribution of major gene products to psoriatic disease has also been investigated through targeting of key immune components, These genes span an array of functions involving innate immunity and adaptive immune responses. ${ }^{3}$ 
Treatments of psoriasis are recommended with systemic drugs, biologic agents, topical therapies, and phototherapy. These can control the disease, but there is no long-term cure. NB-UVB phototherapy is suggested as an alternative major treatment for psoriasis. Mechanisms of this intervention on the pathogenesis of the disease have been investigated during the decade involving DNA damage, production of reactive oxygen species, apoptosis, cell cycle arrest, cellular proliferation, vitamin D synthesis, immunosuppression, and cytokine productions. $^{4-8}$ Advanced laboratory techniques have already been applied in the dermatological field to identify biomarkers and effective treatment, especially inflammatory skin diseases. ${ }^{9,10}$ Recently, next-generation sequencing (NGS) has been introduced with satisfactory results of high efficacy, accuracy, and precision. ${ }^{11-14}$ NGS is used for transcriptomic profiling to compensate for the limitations of the sample size, while avoiding the problem caused by the shortcomings of the microarrays. ${ }^{15}$ Previous studies have shown that genes in lesional psoriatic skin were reported with upregulated gene functions such as immune response and epidermal proliferation. ${ }^{16}$ Significantly, understanding the genetic and immunological basis of psoriasis is expected to lead to the most effective strategy for psoriasis treatment. However, pathogenesis and molecular mechanisms of phototherapy in psoriasis are still controversial and require further studies with advanced genomic techniques.

This study aimed to understand the mechanisms of psoriasis through analyzing differentially expressed genes with RNA-Seq technique by using phototherapy. This research was conducted in patients with moderate-tosevere plaque-type psoriasis who received NB-UVB treatment. RNA sequencing (RNA-Seq) was conducted to assay the transcriptomes and identify differentially expressed transcripts enriched in major pathway analysis. Our results would provide significant molecular results of the pathogenesis of psoriasis and develop new therapeutic modalities for psoriasis treatment in the future. In addition, pathway analysis after phototherapy treatment would be revealed in this analysis.

\section{Materials and Methods}

\section{Patients and Methods}

This study was designed as a single-center, clinical experiment, a before-and-after study was conducted at the dermatology outpatient Benjakitti Park Hospital in Thailand between June 2018 and June 2020. This study was approved by the Human Ethics Committee of Thammasat University No. MTU-EC-OO-2-027/60, conducted according to the principles of the Declaration of Helsinki. Three patients diagnosed with moderate-to-severe plaque psoriasis were enrolled. Signed informed consent was obtained from all patients before enrollment. Study participants were asked to discontinue any systemic treatment and phototherapy for at least 4 weeks, and topical therapies for at least 2 weeks before entering the study. Pregnant and lactating women were also excluded. Patients completed detailed demographic data, including reporting information on comorbidities and concomitant medications. Patients were treated with NB-UVB phototherapy. Before starting phototherapy, the participants' skin type was evaluated. A starting dose of $200-300 \mathrm{~mJ} / \mathrm{cm} 2$ was administrated to the patients using a Waldmann UV5002 cabinet (Villingen-Schwenningen, Germany), which was increased $10 \%$ to $20 \%$ in subsequent session depending on clinical response and skin tolerance until clearance of disease. NBUVB phototherapy was recommended to be conducted in 3 sessions per week with dose increments continued until lesion clearance.

Disease severity and response to therapy were assessed using the psoriasis area severity index (PASI) score before and during treatment. Clinical samples, including skin biopsy samples, were collected at baseline and after successful treatment (PASI 75 reduction). Patients would be followed up every 2 weeks for the first month, then every 4 weeks until the end of the study. Other side effects were investigated such as erythema, tenderness, burning sensation, pruritic symptom. PASI scores were evaluated before, during, and after treatment. Treatment was continued until a $75 \%$ reduction in original PASI score was reached, if the 12-week period had not been completed.

Tissue samples were collected from patients using a 4-mm punch biopsy from psoriasis skin before the start of NB-UVB therapy and 7 days after the last treatment session. To further elucidate molecular alterations in psoriasis, we performed a gene expression study of skin samples. The library preparation process was performed using a TruSeq RNA preparation kit (pair-end, $150 \mathrm{bp}$ ), following the manufacturer's instruction (Bioactive, Thailand). Briefly, purified RNA was randomly fragmented for short-read sequencing and fragmented RNA was reverse transcribed into cDNA. Next, ligate adapters onto both ends of the cDNA fragments. After amplifying fragments using PCR, fragments were selected with insert sizes between 200 and 
$400 \mathrm{bp}$. The cDNA library was sequenced using NextSeq and results were obtained from the DesingStudio program running on a machine. Total RNA was extracted from the frozen biopsies using TRIzolTM Reagent (Ambion) following the manufacturer's instructions. The NGS was performed by a commercial sequencing facility (Macrogen, Seoul, Korea). Briefly, RNA quality and quantity were checked using an Agilent 2100 Bioanalyzer with an RNA Integrity Number (RIN). Libraries for high throughput sequencing were prepared using the SMARTer Universal Low Input RNA Kit, TruSeq RNA Sample Prep Kit v2. The cDNA was checked for quality and quantity on an Agilent 2100 Bioanalyzer. Libraries sequencing was carried out using a NovaSeq 6000 System (Illumina Inc., San Diego, CA, USA) with 100 bp paired-end reads. The quality control of the sequenced raw reads was analyzed. To reduce biases in the analysis, low-quality reads, adaptor sequence, contaminant DNA, or PCR duplicates were removed. Trimmed reads were mapped to the reference genome (UCSC hg19) with HISAT2, splice-aware aligner. A transcript was assembled by StringTie with aligned reads. Gene differential expression analysis was performed with edgeR Bioconductor statistical library version 3.8 on RStudio. ${ }^{17,18}$

The sequencing results were analyzed for quality control of the sequenced raw reads using FastQC. Overall reads quality, total bases, total reads, GC (\%), and basic statistics were calculated. To reduce bias in the analysis, artifacts such as low-quality reads, adaptor sequence, contaminant DNA, or PCR duplicates were removed. Trimmed reads were mapped to reference genome with HISAT2, splice-aware aligner. The transcript was assembled by StringTie with aligned reads. Expression profiles are represented as reading count and normalization value which is based on transcript length and depth of coverage. The FPKM (Fragments Per Kilobase of transcript per Million Mapped reads) value is used as a normalization value.

\section{Functional and Pathway Analysis}

Metascape was employed to perform the gene enrichment and functional annotation analyses. ${ }^{19}$ In addition, functional annotation of these genes was performed using the Database for Annotation, Visualization, and Integrated Discovery. ${ }^{20}$ The lists of significant genes expressed in psoriasis lesions before and after NB-UVB therapy were investigated with Ingenuity Pathway Analysis software (IPA) to identify signaling pathways represented by these genes. ${ }^{21}$ IPA was used in the analysis of biological information, common differential genes, canonical pathways, and upstream regulators. Functional gene analysis was performed using the upstream regulator function in IPA. In addition, the score was acquired by the -log of right-tailed Fisher's exact test. ${ }^{22}$ Overlap $\mathrm{P}$-value and activation $\mathrm{Z}$-score were calculated. $\mathrm{P}<0.05$ was considered to be significant. While, Z-score $>2$ or $<-2$ was considered as significant with a calculation based on the expression association between regulators and genes, and weighted correction. ${ }^{22}$

\section{Results}

To investigate the pathophysiological mechanisms underlying remission of psoriasis with phototherapy, transcriptome profiling was performed with lesion samples before and after the intervention. At the end of treatment, all patients showed clearance of plaque and reached stable remission, which were the hallmark of the end of acute psoriatic inflammation. The characteristics of patients with psoriasis are shown in Table 1.

Differentially expressed coding genes (DEGs) were then identified by comparing the post-treatment with the pre-treatment transcriptomes of each patient. A heatmap and the volcano plot of DEGs show global transcriptome changes in all patients after NB-UVB treatment (Figure 1A and B). A total of 684 DEGs were identified when comparing before and after the intervention, which were 271 upregulated (39.62\%) and 413 downregulated (60.38\%). The top up- or down-regulated DEGs after NBUVB therapy are shown in Tables S1 and $\underline{\mathrm{S} 2}$.

\section{Functional Enrichment and Annotation}

Functional enrichment and annotation for DEGs was analyzed using Metascape with the major sources (Figure 2). ${ }^{19}$ To gain an in-depth understanding, major

Table I Baseline Characteristics of Patients with Psoriasis

\begin{tabular}{|l|c|l|c|c|c|c|c|c|c|c|}
\hline Patient & Age & Sex & PASI Before & PASI After & BMI & Skin Lesion & Scalp Lesion & Nail Lesion & Alcohol & Smoking \\
\hline I & 57 & Male & 12.5 & 2 & 24.4 & Yes & Yes & Yes & No & No \\
2 & 23 & Male & 12.2 & 1 & 20.3 & Yes & Yes & Yes & No & No \\
3 & 39 & Male & 35.5 & 5 & 20.5 & Yes & No & Yes & No & No \\
\hline
\end{tabular}


genes and functions investigated with DAVID Bioinformatics Resources are shown in Table $2 .^{20}$

\section{NB-UVB Therapy Affects Recognized Therapeutic Targets in Psoriasis and Pathway Analysis}

Phototherapy can affect recognized therapeutic targets in psoriasis. IPA was conducted to identify related signaling pathways involved in the mechanism of NB-UVB therapy in psoriasis. Canonical pathway analysis with the IPA software was performed and nine significant pathways were identified (Figure 3A and B). The top significantly changed canonical pathways were "role of IL-17A in psoriasis pathway", "PPAR signaling" "IL-6 signaling", and "p38 MAPK signaling pathway".

All major signaling pathways that were affected by NB-UVB therapy in psoriasis shown in Table 3 and Figure S1. It can be categorized into 4 groups, including NB-UVB regulated pathways that are "immunological signaling pathways", "Cell cycle regulatory, growth, and proliferation pathways", "Therapeutic targets for psoriasis", and others.

\section{Regulatory Network Analysis}

Upstream regulator analysis, based on expected causal effects between upstream regulators and targets, was analyzed to predict upstream molecules associated with changes in gene expression. Upstream regulators have positive z-scores, indicating that their downstream effects were activated whereas upstream regulators with negative z-scores were inhibited downstream effects. The top upstream regulators predicted to be inhibited by z-score are presented in Table 4. TNF was the most predicted inhibited upstream regulators by Z-score after NB-UVB. The top upstream regulators that were predicted to be activated are presented in Table 5. Interestingly, top upstream regulators associated with a molecule of cytokine were analyzed as shown in Table 6 . In addition, the top upstream regulators associated with transmembrane receptors were ranked by absolute z-score and are presented in Table 7. Moreover, the top 50 upstream regulators were predicted to be inhibited and activated attached in Tables $\mathrm{S} 3$ and $\mathrm{S} 4$.

In the Regulatory effects network, STING1, TLR9, IL17C, IL-1A, IL-36A, CD2, IL-17R, NFKBIZ, and TNIP1 were identified as the upstream regulators, which target 27 downstream DEGs, resulting in downregulated effects on immunological cells (phagocytes and granulocytes), proliferation of epithelial cells, growth of connective tissue, and migration of tumor cell lines. Interestingly, STING1 was proposed as a major upstream regulator that can regulate immunological and proliferation of epidermal cells, implying that our analysis may provide insight into new targets for psoriasis (Figure 4).

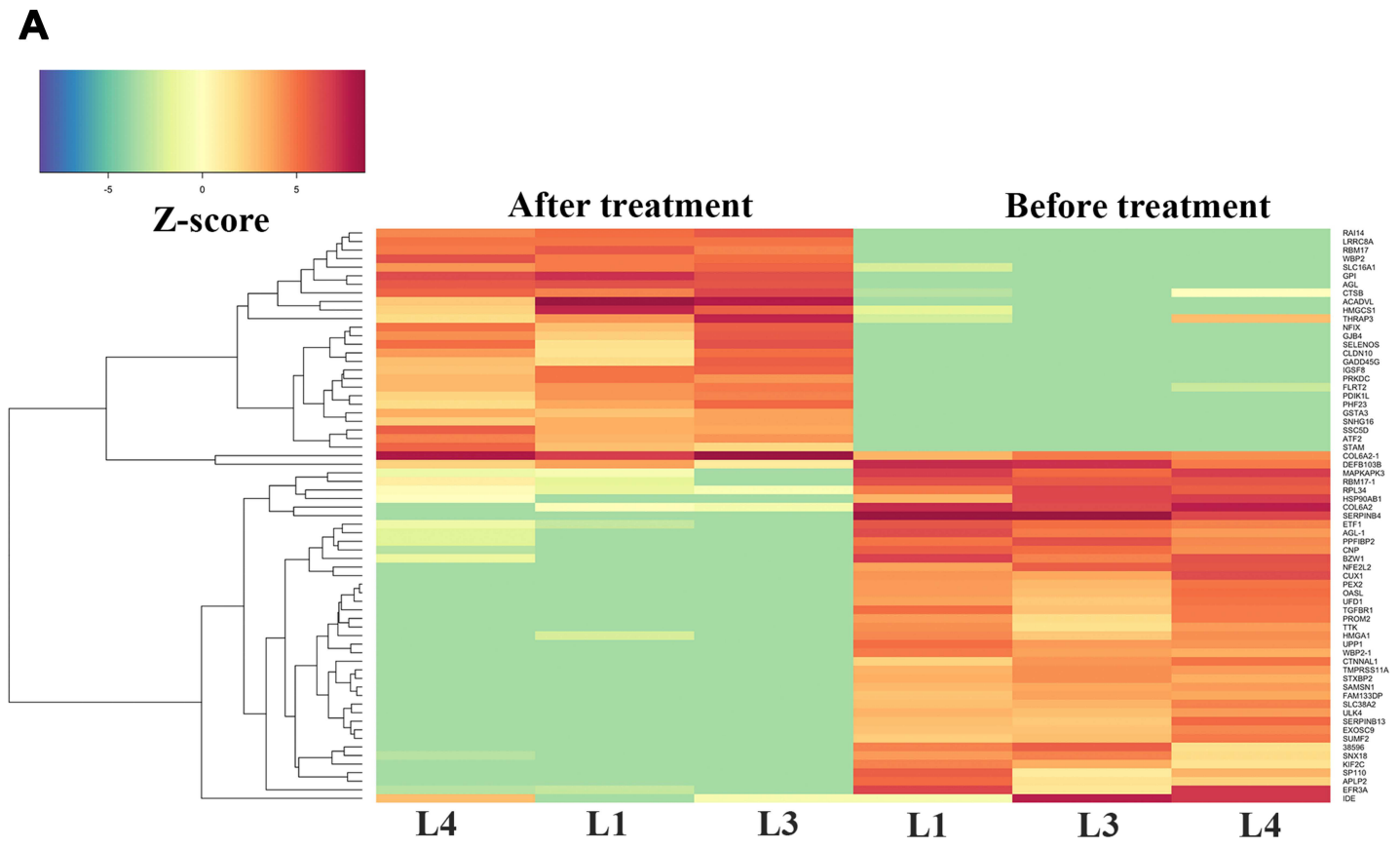

Figure I Continue. 
B

Volcano Plot

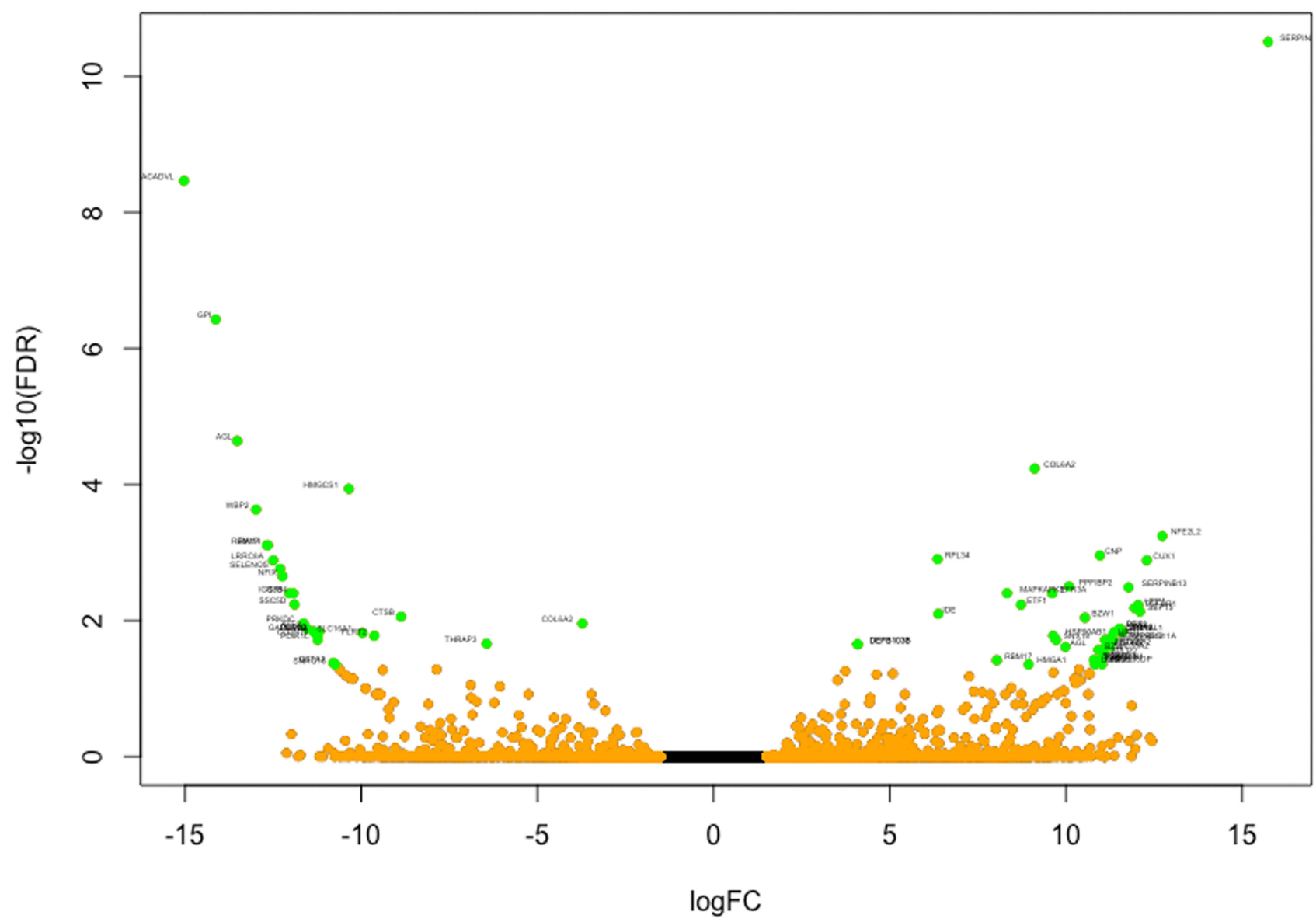

Figure I (A) Heatmap visualization of z-scores for DEGs identified in samples before and after intervention. (B) Volcano plot of RNA-Seq data. The Volcano plot can show differential RNA expression between the two groups (expression of after phototherapy versus before phototherapy). The horizontal line represents a P-value of 0.05 (log 10 scaled). The red dots represent significant differentially-expressed genes, and the black dots represent gene expression that was not significantly different.

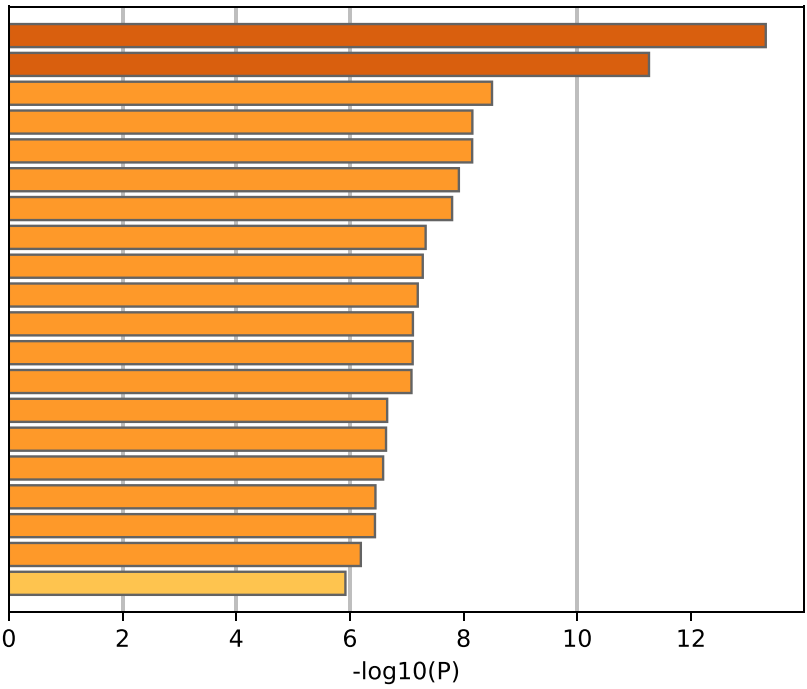

GO:0008544: epidermis development GO:0030162: regulation of proteolysis

GO:0080135: regulation of cellular response to stress R-HSA-109582: Hemostasis

GO:0002237: response to molecule of bacterial origin

GO:0009611: response to wounding

R-HSA-1280215: Cytokine Signaling in Immune system

R-HSA-6799990: Metal sequestration by antimicrobial proteins

R-HSA-9716542: Signaling by Rho GTPases, Miro GTPases and RHOBTB3

GO:1901361: organic cyclic compound catabolic process

GO:0001817: regulation of cytokine production

GO:1904869: regulation of protein localization to Cajal body

GO:0043484: regulation of RNA splicing

GO:0042119: neutrophil activation

GO:0033044: regulation of chromosome organization

GO:0010564: regulation of cell cycle process

GO:0040017: positive regulation of locomotion

WP3888: VEGFA-VEGFR2 Signaling Pathway

GO:0030155: regulation of cell adhesion

GO:0006457: protein folding

Figure 2 Functional enrichment and annotation for DEGs analyzed using Metascape with major sources, including GO Biological Processes, Reactome Gene Sets and WikiPathways. 
Table 2 Significant Down-Regulated Genes Involved with Major Pathogenesis of Psoriasis are Affected by NB-UVB Phototherapy in Psoriasis Lesion Using DAVID Bioinformatics Resources

\begin{tabular}{|c|c|c|c|c|}
\hline & Gene & Symbol & Log Ratio & p-value \\
\hline Epidermis development & $\begin{array}{l}\text { ATP2CI } \\
\text { SI00A7 } \\
\text { CRABP2 } \\
\text { KLK7 } \\
\text { KRTI6 } \\
\text { KRTI7 } \\
\text { PLODI } \\
\text { SPRRIA } \\
\text { SPRRIB } \\
\text { SPRR2A } \\
\text { SPRR2B } \\
\text { SPRR2D } \\
\text { SPRR2F }\end{array}$ & $\begin{array}{l}\text { ATPase secretory pathway } \mathrm{Ca} 2+\text { transporting I(ATP2CI) } \\
\text { SI00 calcium binding protein A7(SI00A7) } \\
\text { Cellular retinoic acid binding protein 2(CRABP2) } \\
\text { Kallikrein related peptidase } 7(\mathrm{KLK} 7) \\
\text { Keratin } 16(\mathrm{KRTI} 6) \\
\text { Keratin I7(KRTI7) } \\
\text { Procollagen-lysine, 2-oxoglutarate 5-dioxygenase I(PLODI) } \\
\text { Small proline rich protein IA(SPRRIA) } \\
\text { Small proline rich protein IB(SPRRIB) } \\
\text { Small proline rich protein 2A(SPRR2A) } \\
\text { Small proline rich protein 2B(SPRR2B) } \\
\text { Small proline rich protein 2D(SPRR2D) } \\
\text { Small proline rich protein 2F(SPRR2F) }\end{array}$ & $\begin{array}{l}-7.457 \\
-3.664 \\
-7.383 \\
-3.767 \\
-5.091 \\
-4.672 \\
-4.411 \\
-2.587 \\
-1.74 \\
-4.449 \\
-2.58 \\
-2.551 \\
-3.517\end{array}$ & $\begin{array}{l}0.0133 \\
-3.664 \\
0.000648 \\
0.0453 \\
0.000284 \\
0.0364 \\
0.00324 \\
0.0212 \\
0.039 \\
0.000943 \\
0.0104 \\
0.00634 \\
0.000398\end{array}$ \\
\hline Cell division & $\begin{array}{l}\text { MAD2L2 } \\
\text { SETDB2 } \\
\text { BIRC5 } \\
\text { CSNKIAI } \\
\text { CDC25A } \\
\text { CENPF } \\
\text { CCNA2 } \\
\text { CCNBI } \\
\text { KIF2OB } \\
\text { KIF2C } \\
\text { PTTGI } \\
\text { PPPICC } \\
\text { PPP2R2D } \\
\text { RNF8 } \\
\text { STAG2 } \\
\text { TACCI }\end{array}$ & $\begin{array}{l}\text { MAD2 mitotic arrest deficient-like } 2 \text { (yeast)(MAD2L2) } \\
\text { SET domain bifurcated 2(SETDB2) } \\
\text { Baculoviral IAP repeat containing 5(BIRC5) } \\
\text { Casein kinase I alpha I(CSNKIAI) } \\
\text { Cell division cycle 25A(CDC25A) } \\
\text { Centromere protein F(CENPF) } \\
\text { Cyclin A2(CCNA2) } \\
\text { Cyclin BI(CCNBI) } \\
\text { Kinesin family member 20B(KIF20B) } \\
\text { Kinesin family member 2C(KIF2C) } \\
\text { Pituitary tumor-transforming I(PTTGI) } \\
\text { Protein phosphatase I catalytic subunit gamma(PPPICC) } \\
\text { Protein phosphatase } 2 \text { regulatory subunit Bdelta(PPP2R2D) } \\
\text { Ring finger protein 8(RNF8) } \\
\text { Stromal antigen 2(STAG2) } \\
\text { Transforming acidic coiled-coil containing protein I(TACCI) }\end{array}$ & $\begin{array}{l}-7.187 \\
-9.154 \\
-9.644 \\
-9.284 \\
-5.608 \\
-2.811 \\
-3.178 \\
-2.671 \\
-2.833 \\
-11.028 \\
-10.162 \\
-5.216 \\
-8.906 \\
-6.833 \\
-10.386 \\
-8.934\end{array}$ & $\begin{array}{l}0.0318 \\
0.0467 \\
0.00027 \\
0.046 \\
0.00641 \\
0.00328 \\
0.00721 \\
0.0318 \\
0.0274 \\
0.00018 \\
0.0324 \\
0.0313 \\
0.0426 \\
0.0194 \\
0.0404 \\
0.0252\end{array}$ \\
\hline
\end{tabular}




\begin{tabular}{|c|c|c|c|c|}
\hline Cell-cell adherent junction & $\begin{array}{l}\text { LASPI } \\
\text { LMO7 } \\
\text { RANBPI } \\
\text { ANLN } \\
\text { ANXAI } \\
\text { BZWI } \\
\text { BZW2 } \\
\text { CDH3 } \\
\text { CALDI } \\
\text { CTNNDI } \\
\text { CHMP5 } \\
\text { DSC2 } \\
\text { FLOTI } \\
\text { HSP9OABI } \\
\text { KTNI } \\
\text { PPMEI } \\
\text { RPL34 } \\
\text { STK24 } \\
\text { TMPO } \\
\text { TJPI } \\
\text { TWFI }\end{array}$ & $\begin{array}{l}\text { LIM and SH3 protein I(LASPI) } \\
\text { LIM domain 7(LMO7) } \\
\text { RAN binding protein I(RANBPI) } \\
\text { Anillin actin binding protein(ANLN) } \\
\text { Annexin AI(ANXAI) } \\
\text { Basic leucine zipper and W2 domains I(BZWI) } \\
\text { Basic leucine zipper and W2 domains 2(BZW2) } \\
\text { Cadherin 3(CDH3) } \\
\text { Caldesmon I(CALDI) } \\
\text { Catenin delta I(CTNNDI) } \\
\text { Charged multivesicular body protein 5(CHMP5) } \\
\text { Desmocollin 2(DSC2) } \\
\text { Flotillin I(FLOTI) } \\
\text { Heat shock protein 90 alpha family class B member I(HSP90ABI) } \\
\text { Kinectin I(KTNI) } \\
\text { Protein phosphatase methylesterase I(PPMEI) } \\
\text { Ribosomal protein L34(RPL34) } \\
\text { Serine/threonine kinase 24(STK24) } \\
\text { Thymopoietin(TMPO) } \\
\text { Tight junction protein I(TJPI) } \\
\text { Twinfilin actin binding protein I(TWFI) }\end{array}$ & $\begin{array}{l}-9.115 \\
-2.211 \\
-2.683 \\
-10.681 \\
-2.04 \\
-10.922 \\
-5.762 \\
-1.694 \\
-3.857 \\
-10.396 \\
-1.815 \\
-5.116 \\
-5.013 \\
-9.639 \\
-3.715 \\
-8.728 \\
-6.358 \\
-5.568 \\
-8.71 \\
-9.751 \\
-5.981\end{array}$ & $\begin{array}{l}0.0121 \\
0.0156 \\
0.0301 \\
0.000294 \\
0.0175 \\
0.0000952 \\
0.0206 \\
0.0316 \\
0.0308 \\
0.0437 \\
0.0446 \\
0.0278 \\
0.0476 \\
0.0000464 \\
0.00133 \\
0.0251 \\
0.000000907 \\
0.0243 \\
0.017 \\
0.0424 \\
0.028\end{array}$ \\
\hline
\end{tabular}

(Continued) 
Table 2 (Continued).

\begin{tabular}{|c|c|c|c|c|}
\hline & Gene & Symbol & Log Ratio & p-value \\
\hline \multirow[t]{35}{*}{ Inflammatory response and Immunity } & \multicolumn{4}{|c|}{ Cytokine and chemokine activity } \\
\hline & SPI00 & SPI00 nuclear antigen(SPI00) & -3.352 & 0.0499 \\
\hline & IL36RN & Interleukin 36 receptor antagonist(IL36RN) & -2.585 & 0.0486 \\
\hline & IL36A & Interleukin 36, alpha(IL36A) & -10.156 & 0.00224 \\
\hline & IL36G & Interleukin 36, gamma(IL36G) & -3.612 & 0.00203 \\
\hline & NAMPT & Nicotinamide phosphoribosyltransferase(NAMPT) & -1.623 & 0.0429 \\
\hline & CXCL8 & C-X-C motif chemokine ligand 8(CXCL8) & -9.997 & 0.00121 \\
\hline & \multicolumn{4}{|c|}{ Positive regulation of NF-kB transcription factor activity } \\
\hline & CLU & Clusterin(CLU) & -7.093 & 0.0325 \\
\hline & IKBKB & Inhibitor of kappa light polypeptide gene enhancer in B-cells, kinase beta(IKBKB) & -8.495 & 0.0236 \\
\hline & NPMI & Nucleophosmin(NPMI) & -1.676 & 0.0427 \\
\hline & RPS6KA4 & Ribosomal protein S6 kinase A4(RPS6KA4) & -7.07 & 0.0494 \\
\hline & \multicolumn{4}{|l|}{ Innate immunity } \\
\hline & SIOOAI2 & SI00 calcium binding protein $\mathrm{A} \mid 2(\mathrm{SIO0A} / 2)$ & -8.161 & 0.0441 \\
\hline & SI00A8 & S100 calcium binding protein $\mathrm{A} 8(\mathrm{~S} 100 \mathrm{~A} 8)$ & -4.491 & 0.0106 \\
\hline & SI00A9 & SI00 calcium binding protein $A 9(S 100 A 9)$ & -5.832 & 0.00372 \\
\hline & LCN2 & Lipocalin 2(LCN2) & -5.05 & 0.0173 \\
\hline & \multicolumn{4}{|c|}{ Type I interferon signaling pathway } \\
\hline & OAS2 & 2'-5'-oligoadenylate synthetase 2 (OAS2) & -2.737 & 0.00906 \\
\hline & OASL & 2'-5'-oligoadenylate synthetase like(OASL) & -11.523 & 0.0000271 \\
\hline & SPI00 & SPI00 nuclear antigen(SPI00) & -3.352 & 0.0499 \\
\hline & ADAR & Adenosine deaminase, RNA specific(ADAR) & -11.034 & 0.0117 \\
\hline & \multicolumn{4}{|l|}{ Others } \\
\hline & CLEC7A & C-type lectin domain family 7 member $A(C L E C 7 A)$ & -9.153 & 0.00128 \\
\hline & MEFV & Mediterranean fever(MEFV) & -7 & 0.012 \\
\hline & POLR3F & RNA polymerase III subunit F(POLR3F) & -4.442 & 0.0386 \\
\hline & CIQBP & Complement $\mathrm{Cl} \mathrm{q}$ binding protein(CIQBP) & -1.994 & 0.0269 \\
\hline & HMGB3 & High mobility group box 3(HMGB3) & -4.795 & 0.0153 \\
\hline & IFII 6 & Interferon gamma inducible protein I6(IFII6) & -1.806 & 0.04 \\
\hline & JAML & Junction adhesion molecule like(JAML) & -5.983 & 0.00513 \\
\hline & HLA-DPAI & Major histocompatibility complex, class II, DP alpha I(HLA-DPAI) & -2.442 & 0.0253 \\
\hline & PTPN22 & Protein tyrosine phosphatase, non-receptor type 22(PTPN22) & -3.779 & 0.0309 \\
\hline & TNIP3 & TNFAIP3 interacting protein $3($ TNIP3) & -5.305 & 0.00153 \\
\hline & ACKR2 & Atypical chemokine receptor 2(ACKR2) & -3.938 & 0.034 \\
\hline & GBP5 & Guanylate binding protein 5(GBP5) & -3.794 & 0.0417 \\
\hline
\end{tabular}




\section{A}

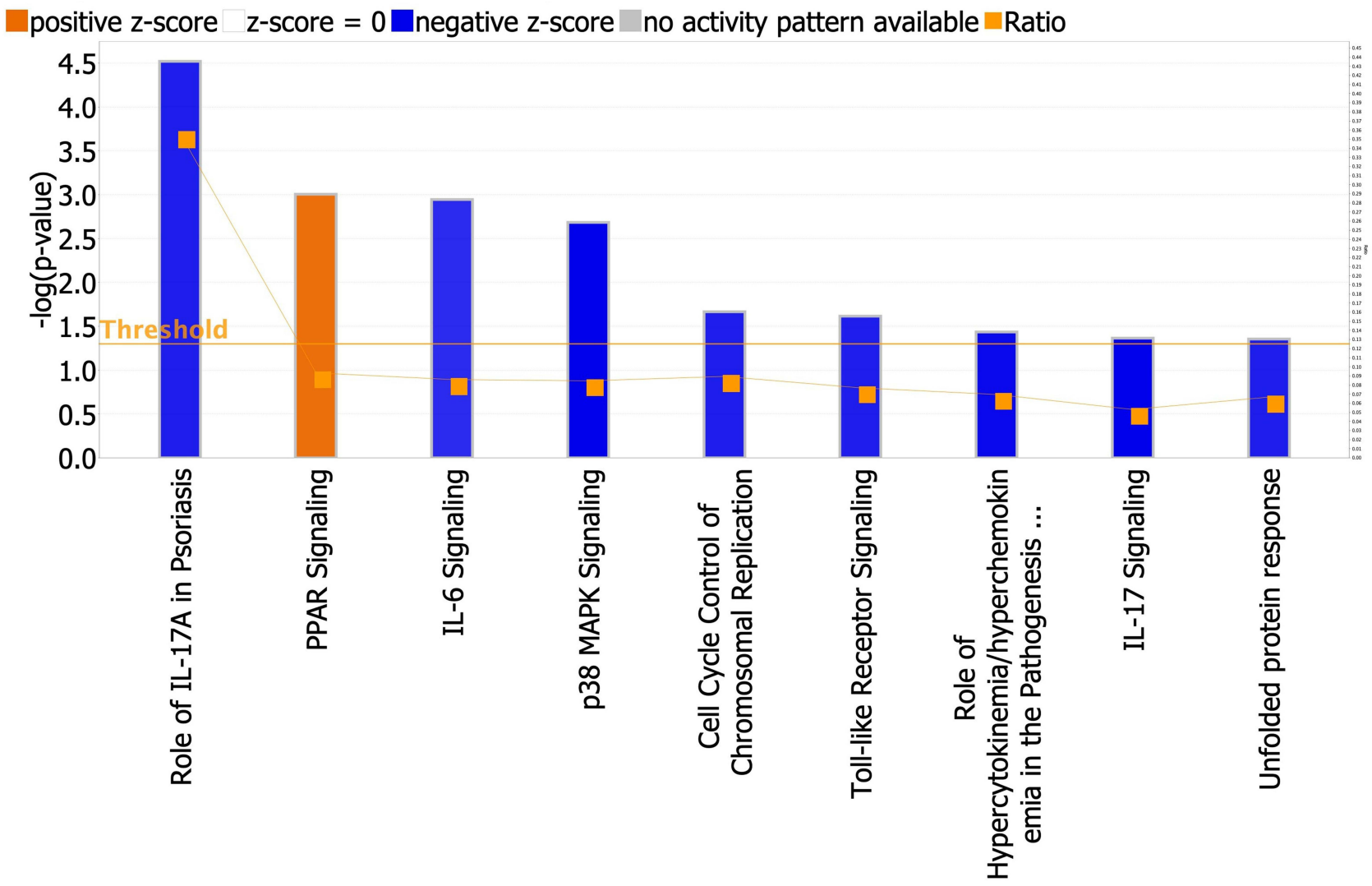

Figure 3 Continue.

\section{Discussion}

UVB radiation has been considered to be an effective treatment for psoriasis for decades. This is a potent immunosuppressive intervention that can improve clinical outcomes with prominent inhibition of cell-mediated immune response. ${ }^{3}$ Previous researches have been conducted to investigate the efficacy of NB-UVB in psoriasis. However, immunopathogenesis and genetic aspects have not been completely elucidated. ${ }^{23-25}$ In this study, considering that psoriasis is an autoinflammatory disease with systemic inflammation, this result suggests that NB-UVB in psoriasis treatment is significantly associated with a change of functional enrichment and annotation with significant enrichment in clusters of immune responses, including "cytokine signaling in immune response", "regulation of cytokine production", and "neutrophil activation". In addition, NB-UVB strongly suppressed genes of the epidermis development, immunity, and inflammatory response. The expressions of other genes involved in cell division and cell-cell adherent junction were also inhibited after the intervention. To gain a greater understanding at a systems level of phototherapy, we focused on canonical pathways analysis. The result showed that NB-UVB treatment played a significant role in psoriasis improvement, associated with "immunological signaling pathways" and "cell cycle regulatory, growth, and proliferation pathways".

Within our data, after NB-UVB treatment in lesional psoriasis, immunological signaling pathways were inhibited with the down expression of inflammatory and cytokine-related genes. "Role of IL-17A in psoriasis and IL-17 pathway" were major inhibited canonical pathways after NB-UVB treatment within the results with significant downregulation of expression of genes. These results are in agreement with previous studies suggesting that the mechanism of UVB phototherapy is directly involved in the IL-17 signaling pathway. ${ }^{8,23,25-27}$ A published study in 2017 revealed additional mechanisms of UVB phototherapy with blockage of IL-17A/TNF- $\alpha$-induced IL-6, IL-8, and CXCL-1 production and decreased an expression of IL-17RA and IL-17RC on fibroblasts through the TGF- $\beta 1$ / Smad3 pathway. ${ }^{28}$ The result is evidence of a correlation 


\section{B}

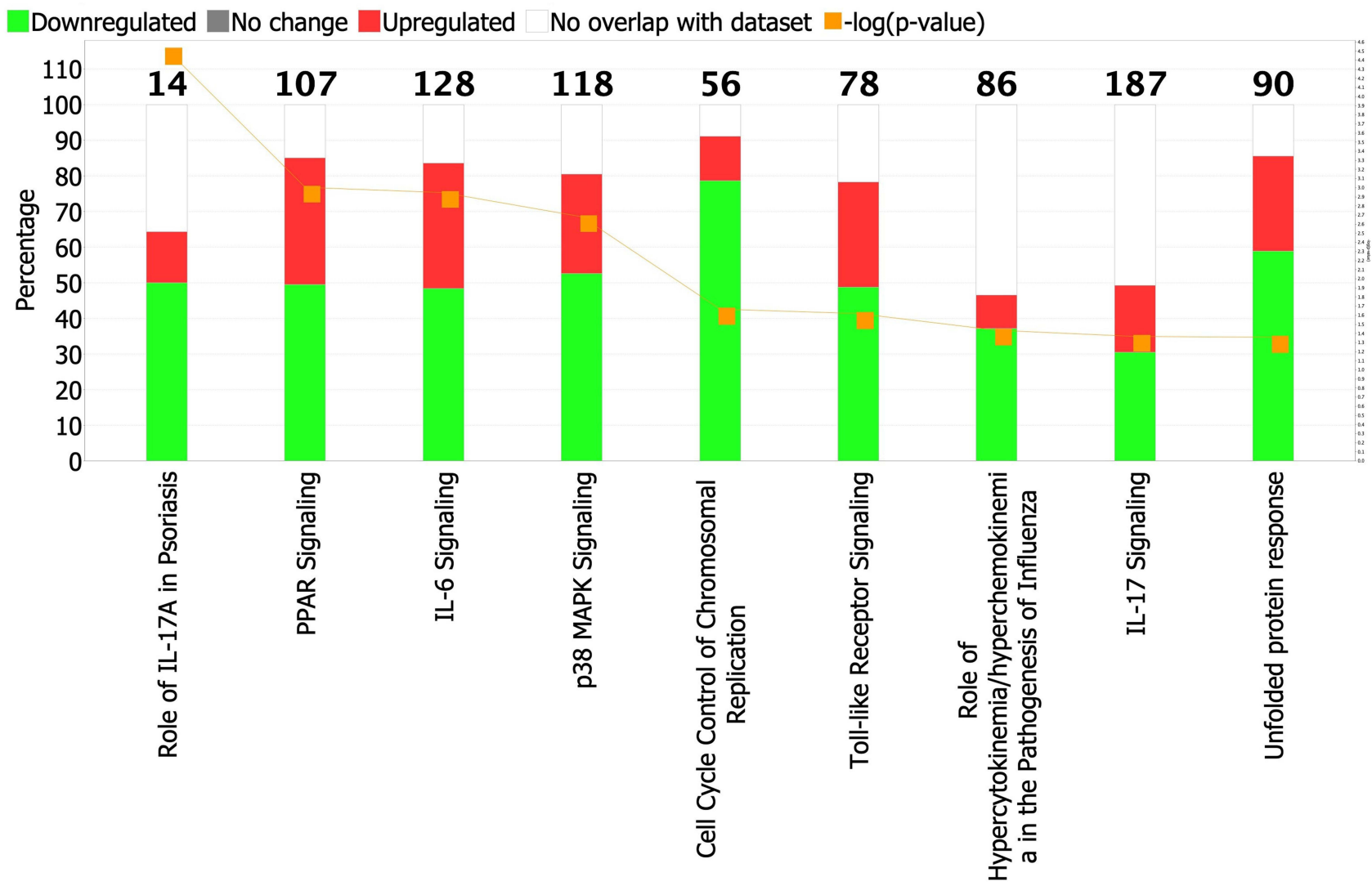

Figure 3 (A) Pathway analysis. Enrichment of top clusters for significant DEGs was analyzed with $-\log ($ FDR) $=1.3$ and an absolute value of z-score $>2$. The height of the bars represents the probability that the DEGs in the dataset are related to each pathway. The Orange bars show predicted pathway activation, and the blue bars show predicted pathway inhibition. The Orange points connected by a line represent the ratio which presents the proportion of DEGs in the datasets that map to each canonical pathway. (B) Pathway analysis with the percentage of upregulated DEGs (red segment of bar), the percentage of downregulated DEGs (green segment of bar) and overlaps in each pathway. Percentage of non-overlapped DEGs to the pathways is shown by the white segment of the bar. The number of molecules in each known pathway are shown on the top of the bar.

between regulated genes in major significant pathways and response to treatment. Interestingly, most well-known psoriasis-related genes were inhibited with phototherapy in lesional psoriasis, such as CXCL8, DEFB4A/DEFB4B, S100A7, S100A8, S100A9, DEFB103B. ${ }^{25,29,30}$ Furthermore, a significant reduction of inflammatoryrelated genes involved in IL-17 signaling was demonstrated, particularly IL-36A, IL-36G, HRAS, HSP90AB1, LCN2, NOS2. Results also align with previous researches suggesting that IL-36G is hallmark psoriasis gene in psoriasis lesions. $^{31,32}$ Notedly, the inhibited genes of IL-36 cytokines were predominantly expressed in other pathways in this analysis, including the downregulated of IL-17 signaling, p38 MAPK signaling, acute phase response signaling, toll-like receptor signaling, the role of hypercytokinemia/hyperchemokinemia in the pathogenesis of influenza, and LXR/RXR activation. According to this result, we proposed that one of the mechanisms of NBUVB in psoriasis treatment was to inhibit IL-36 cytokines that were classified in an IL-1 family involved in the innate and adaptive immunity. ${ }^{33,34}$ In addition, this major finding is consistent with previous research showing that mutations of IL-36RN were a demonstrated risk for generalized pustular psoriasis and alteration of IL-36 cytokines was reported with increased severity of the disease in the early onset. ${ }^{35}$ As a result, our research highlights that IL-36 cytokines are interesting genetic markers that should be investigated in further study.

We extended these results to investigate the most prominent impact of NB-UVB therapy on the significant decrease in gene expression of inflammatory cytokines in transcriptomic analysis. It may be hypothesized that the effect of phototherapy on the expression of cytokines in lesional psoriasis may be explained by the reduction in the release of the proinflammatory mediators from inflamed skin. $^{36-38}$ The upstream regulator candidates were presented with predicted inhibition of inflammatory cytokines which were reported in pathogenesis of psoriasis, 
Table 3 Effect of NB-UVB Phototherapy on Major Pathways in Psoriasis

\begin{tabular}{|c|c|c|c|c|}
\hline \multirow[t]{2}{*}{ Name } & \multirow[t]{2}{*}{ p-value } & \multirow{2}{*}{$\begin{array}{l}\text { Activation } \\
\text { z-Score }\end{array}$} & \multicolumn{2}{|l|}{ Molecules Affected by NB-UVB Within These Pathways } \\
\hline & & & Downregulated & Upregulated \\
\hline \multicolumn{5}{|l|}{ Immunological signaling pathways } \\
\hline Role of IL-17A in psoriasis & $3.26 \mathrm{E}-05$ & -2.236 & CXCL8, DEFB4A/DEFB4B, SI00A7, SI00A8, SI00A9 & \\
\hline IL-6 signaling & $1.12 \mathrm{E}-03$ & -2.111 & CXCL8, HRAS, IKBKB, IL36A, IL36G, IL36RN, MAP4K4, SOCS3, STAT3 & COLIAI, CSNK2A2 \\
\hline p38 MAPK signaling & $2.232 \mathrm{E}-03$ & -2.53 & IL36A, IL36G, IL36RN, MAPKAPK3, PLA2G4D, RPS6KA4, TGFBRI, H3CI4 & ATF2, EEF2K \\
\hline Acute phase response signaling & $6.45 \mathrm{E}-03$ & -1.058 & $\begin{array}{l}\text { HRAS, IL36RN, IL36G, SOCS3, SERPINA3, STAT3, CRABP2, SOD2, IKBKB, } \\
\text { IL36A }\end{array}$ & OSMR, FNI \\
\hline Toll-like receptor signaling & $2.30 \mathrm{E}-02$ & -2.236 & IKBKB, IL36A, IL36G, IL36RN, MAP4K4, UBD & \\
\hline $\begin{array}{l}\text { Role of hypercytokinemia /hyperchemokinemia in the } \\
\text { pathogenesis of influenza }\end{array}$ & $3.90 \mathrm{E}-02$ & -2.449 & CXCL8, IL36A, IL36G, IL36RN, OAS2 & SIPRI \\
\hline IL-I7 signaling & 4.67E-02 & -2.53 & $\begin{array}{l}\text { CXCL8, HRAS, HSP90ABI, IL36A, IL36G, LCN2, NOS2 } \\
\text { DEFBI03A/DEFBI03B } \\
\text { DEFB4A/DEFB4B }\end{array}$ & ATF2 \\
\hline \multicolumn{5}{|c|}{ Cell cycle regulatory, growth, and proliferation pathways } \\
\hline ATM signaling & 7.24E-03 & 0.816 & CCNBI, PPPICC, CDC25A, RNF8 & $\begin{array}{l}\text { ATF2, GADD45G, } \\
\text { MDM4, BRATI }\end{array}$ \\
\hline Ferroptosis signaling pathway & $3.06 \mathrm{E}-02$ & 0.707 & CTSB, ALOXI5, SLCIIA2 & $\begin{array}{l}\text { H2AFY, HRAS, STAT3, } \\
\text { CHACI, NFE2L2 }\end{array}$ \\
\hline Kinetochore metaphase signaling pathway & $7.08 \mathrm{E}-04$ & -1.897 & $\begin{array}{l}\text { BIRC5, CCNBI, KIF2C, H2AFY, MAD2L2, PPPICC, PTTGI, STAG2, TTK, } \\
\text { MACROH2AI }\end{array}$ & $\mathrm{CDC} 27$ \\
\hline Senescence pathway & $6.82 \mathrm{E}-03$ & -1.807 & $\begin{array}{l}\text { HRAS, CCNBI, CDC25A, RPS6KA4, HBPI, SOD2, PDK2, MAPKAPK3, IKBKB, } \\
\text { CXCL8, PDHAI, ITSN2, TGFBRI, ZFP36LI }\end{array}$ & $\begin{array}{l}\text { GADD } 45 G, \text { CDC27, } \\
\text { ZFP36LI }\end{array}$ \\
\hline Cell cycle control of chromosomal replication & 2.29E-02 & -2.236 & CDC45, CDK16, DNA2, POLDI, TOP2A & \\
\hline FATIO cancer signaling pathway & I.04E-02 & -1.342 & IKBKB, MAD2L2, STAT3, TGFBRI, UBD & \\
\hline \multicolumn{5}{|l|}{ Therapeutic target in psoriasis } \\
\hline PPAR signaling & $9.59 \mathrm{E}-04$ & 2.53 & $\begin{array}{l}\text { HRAS, HSP90ABI, IKBKB, IL36A, IL36G, IL36RN, MAP4K4, NCORI, PPARD, } \\
\text { CITED2 }\end{array}$ & \\
\hline LXR/RXR activation & $2.48 \mathrm{E}-02$ & 1.89 & CLU, IL36A, IL36G, IL36RN, NCORI, NOS2, SI00A8 & APOE \\
\hline Sirtuin signaling pathway & $4.55 \mathrm{E}-02$ & 0.577 & $\begin{array}{l}\text { NAMPT, HIST2H3C, STAT3, NOS2, NDUFA5, GABPA, SOD2, VDACI, } \\
\text { CXCL8, PDHAI, PFKM, NFE2L2 }\end{array}$ & PRKDC, GADD45G \\
\hline \multicolumn{5}{|l|}{ Other } \\
\hline Neuroprotective role of THOPI in alzheimer's disease & $1.98 \mathrm{E}-02$ & -1.342 & KLK7, SERPINA3, TMPRSSIID, PRSS22, IDE, TMPRSSIIA & PRKARIA, ACE \\
\hline Unfolded protein response & $2.29 \mathrm{E}-02$ & -2.236 & CANX, CEBPA, NFE2L2, PDIA6, XBPI, DNAJCIO & \\
\hline
\end{tabular}


Table 4 Top 20 Upstream Regulators Were Predicted to Be Inhibited by z-Score

\begin{tabular}{|c|c|c|c|}
\hline Upstream Regulator & Molecule Type & Activation z-Score & p-value of Overlap \\
\hline TNF & Cytokine & -4.94 & 0.00000301 \\
\hline ILIA & Cytokine & -4.357 & 0.0000528 \\
\hline ILIB & Cytokine & -4.144 & 0.00000018 \\
\hline Poly rl:rC-RNA & Biologic drug & -4.144 & 0.000042 \\
\hline IFNG & Cytokine & -3.942 & 0.000000325 \\
\hline EHF & Transcription regulator & -3.873 & 0.000000127 \\
\hline Lipopolysaccharide & Chemical drug & -3.85 & 7.64E-08 \\
\hline IL22 & Cytokine & -3.535 & $2.29 \mathrm{E}-08$ \\
\hline IL2। & Cytokine & -3.485 & 0.00224 \\
\hline IRF3 & Transcription regulator & -3.405 & 0.00345 \\
\hline CEBPB & Transcription regulator & -3.241 & $4.26 \mathrm{E}-08$ \\
\hline OSM & Cytokine & -3.203 & $6.43 \mathrm{E}-15$ \\
\hline AREG & Growth factor & -3.162 & 0.000253 \\
\hline STATI & Transcription regulator & -3.149 & 0.00000179 \\
\hline IFNLI & Cytokine & -3.101 & 0.00021 \\
\hline Thapsigargin & Chemical toxicant & -3.079 & 0.0104 \\
\hline IRF7 & Transcription regulator & -3.078 & 0.000676 \\
\hline LIF & Cytokine & -3.062 & 0.0278 \\
\hline CSF2 & Cytokine & -3.057 & 0.0000525 \\
\hline Isotretinoin & Biologic drug & -3.053 & 0.000000251 \\
\hline
\end{tabular}

Abbreviation: poly rl:rC RNA, polyinosinic-cytidylic acid RNA.

including TNF, IL-1A, IL-1B, IFNG, IL-22, IL-21, OSM, IFN- $\gamma$ inducing other cytokines. ${ }^{39-41}$ Improvement in psorIFNL1 after the intervention. These results are consistent iatic skin following phototherapy may involve the with others reported in the literature, suggesting that NB- decreased expression of inflammatory cytokine IFN- $\gamma .{ }^{40}$ UVB therapy has effects on the expression of TNF and Recent researches have shown that IFN-mediated

Table 5 Top 20 Upstream Regulators Were Predicted to Be Activated by Z-Score

\begin{tabular}{|c|c|c|c|}
\hline Upstream Regulator & Molecule Type & Activation z-Score & p-value of Overlap \\
\hline KMT2D & Transcription regulator & 3.081 & 0.0000284 \\
\hline ILIRN & Cytokine & 2.935 & 0.0152 \\
\hline Irgm I & Other & 2.932 & 0.00235 \\
\hline mir- $^{21}$ & microRNA & 2.876 & 0.00000408 \\
\hline Zinc & Chemical drug & 2.815 & 0.003 \\
\hline GATA I & Transcription regulator & 2.813 & 0.0525 \\
\hline Sn50 peptide & Chemical toxicant & 2.611 & 0.00264 \\
\hline SPARC & Other & 2.556 & 0.0451 \\
\hline Bexarotene & Chemical drug & 2.537 & 0.00491 \\
\hline KLF3 & Transcription regulator & 2.496 & 0.175 \\
\hline Napabucasin & Chemical drug & 2.449 & 0.0111 \\
\hline miR-483-3p (miRNAs w/seed CACUCCU) & Mature microRNA & 2.437 & 0.00191 \\
\hline ILIORA & Transmembrane receptor & 2.435 & 0.000967 \\
\hline TNIPI & Other & 2.433 & 0.00117 \\
\hline SOCSI & Other & 2.418 & 0.0234 \\
\hline Baicalein & Chemical drug & 2.407 & 0.00191 \\
\hline PIK3CG & Kinase & 2.391 & 0.0365 \\
\hline NS-398 & Chemical reagent & 2.369 & 0.032 \\
\hline BCL6 & Transcription regulator & 2.359 & 0.0246 \\
\hline MRTFA & Transcription regulator & 2.335 & 0.1 \\
\hline
\end{tabular}


Table 6 Top Upstream Regulators Associated with a Molecule of Cytokine by Z-Score

\begin{tabular}{|l|c|c|}
\hline $\begin{array}{l}\text { Upstream } \\
\text { Regulator }\end{array}$ & $\begin{array}{c}\text { Activation } \\
\text { z-Score }\end{array}$ & $\begin{array}{c}\text { p-value of } \\
\text { Overlap }\end{array}$ \\
\hline TNF & -4.94 & 0.0000030 I \\
ILIA & -4.357 & 0.0000528 \\
ILIB & -4.144 & 0.00000018 \\
IFNG & -3.942 & 0.000000325 \\
IL22 & -3.535 & $2.29 \mathrm{E}-08$ \\
IL2I & -3.485 & 0.00224 \\
OSM & -3.203 & $6.43 \mathrm{E}-15$ \\
IFNLI & -3.101 & 0.00021 \\
LIF & -3.062 & 0.0278 \\
CSF2 & -3.057 & 0.0000525 \\
ILIRN & 2.935 & 0.0152 \\
\hline
\end{tabular}

signaling cascade was associated with activation of the receptor-associated JAK-STAT signaling pathway, and with major signaling pathways, the NF- $\mathrm{BB}$ signaling pathway, and p38 MAPK signaling pathway. ${ }^{42-46}$ UVB radiation could regulate anti-inflammatory effects with alteration on expression of IL-1/ IL-6 inflammatory axis by different mechanisms. ${ }^{47}$ Another finding in our study was that OSM, a cytokine secreted by skin-infiltrating $\mathrm{T}$ lymphocytes, was in downregulated genes of an upstream regulator network after phototherapy. Significantly, IL-10RA was shown as the upstream regulator candidate with predicted activation. In sum, our study suggests that NB-UVB irradiation alleviates inflammation by decreasing the expression of inflammatory cytokines and enhances the synthesis of an anti-inflammatory cytokine receptor. Our evidence suggested that "IL-6 signaling" was a major inhibited pathway after treatment with phototherapy. Previous studies investigated the effect of

Table 7 Top Upstream Regulators Associated with a Transmembrane Receptor by Z-Score

\begin{tabular}{|l|c|c|}
\hline $\begin{array}{l}\text { Upstream } \\
\text { Regulator }\end{array}$ & $\begin{array}{c}\text { Activation } \\
\text { z-Score }\end{array}$ & $\begin{array}{c}\text { p-value of } \\
\text { Overlap }\end{array}$ \\
\hline TLR3 & -2.895 & 0.0238 \\
IFNARI & -2.771 & 0.00703 \\
TLR9 & -2.744 & 0.0302 \\
TNFRSFIA & -2.439 & 0.113 \\
TLR4 & -2.334 & 0.12 \\
CD40 & -2.159 & 0.213 \\
CD2 & -2 & 0.0367 \\
ILIORA & 2.435 & 0.000967 \\
\hline
\end{tabular}

UVB on an alteration of production and expression of IL-6 and mechanisms of transcription of the IL- 6 gene through signal transduction of JAK/STAT, MAPK, and NF- $\mathrm{KB}$ signaling pathway. ${ }^{47,48}$ The results from this study suggest that the efficacy of NB-UVB treatment is directly linked to mechanisms of action through downregulated immunological signaling pathways, including downregulated "p38 MAPK signaling" and "pathway of acute phase response signaling”. Although, UVB irradiation can activate epidermal p38 MAPK signaling and induces a local proinflammatory response in the early stage. ${ }^{49,50} \mathrm{NB}-\mathrm{UVB}$ treatment can induce chronic effect of UVB which may cause downregulation of p38 MAPK pathway. Downregulated p38 MAPK signaling after NB-UVB in this study may propose p38 MAPK as a potential target for treatment with decreased stress response genes, inflammatory cytokines, and apoptosis with the indirect mechanisms.

The abnormal proliferation of keratinocytes in psoriatic lesions is important in the pathogenesis of psoriasis. Keratinocyte can absorb NB-UVB irradiation and is considered to be the major target for regulating plaque mitigation in chronic psoriasis. ${ }^{51}$ We propose that keratinocyte differentiation and proliferation can be regulated with genes in signaling pathways and inflammatory mediators related to cell proliferation and apoptosis. ATF2 and GADD45G gene were presented with upregulation in major signaling pathways after phototherapy. GADD45 gene induced by DNA damage and other stress signals associated with growth arrest, cell cycle control, and apoptosis were reported with upregulated after exposure to ultraviolet (UV) radiation. ${ }^{52}$ Our results also support previous research, reporting that GADD45 has an important role in maintaining genomic integrity and DNA repair in keratinocytes exposed to UV. ${ }^{53}$ ATF2, which can also activate targeting genes of GADD45, is a regulator of apoptosis and expression of proteins of controlling cell cycle and programmed cell death. ${ }^{54,55}$ It was claimed that this gene can be activated following UV irradiation. ${ }^{56}$ However, there was no specific data reported that this gene functioned in association with NB-UVB in psoriasis treatment. Moreover, we reported inhibited expression of IL-22 and IL-21, which are immunoinflammatory mediators for psoriasis, may have a positive effect on clinical outcomes linked to the clearing of lesional psoriasis after NB-UVB. ${ }^{6}$ IL-22 is considered as the primary promoter of keratinocyte and epidermal hyperproliferation, and dermal inflammation that is 


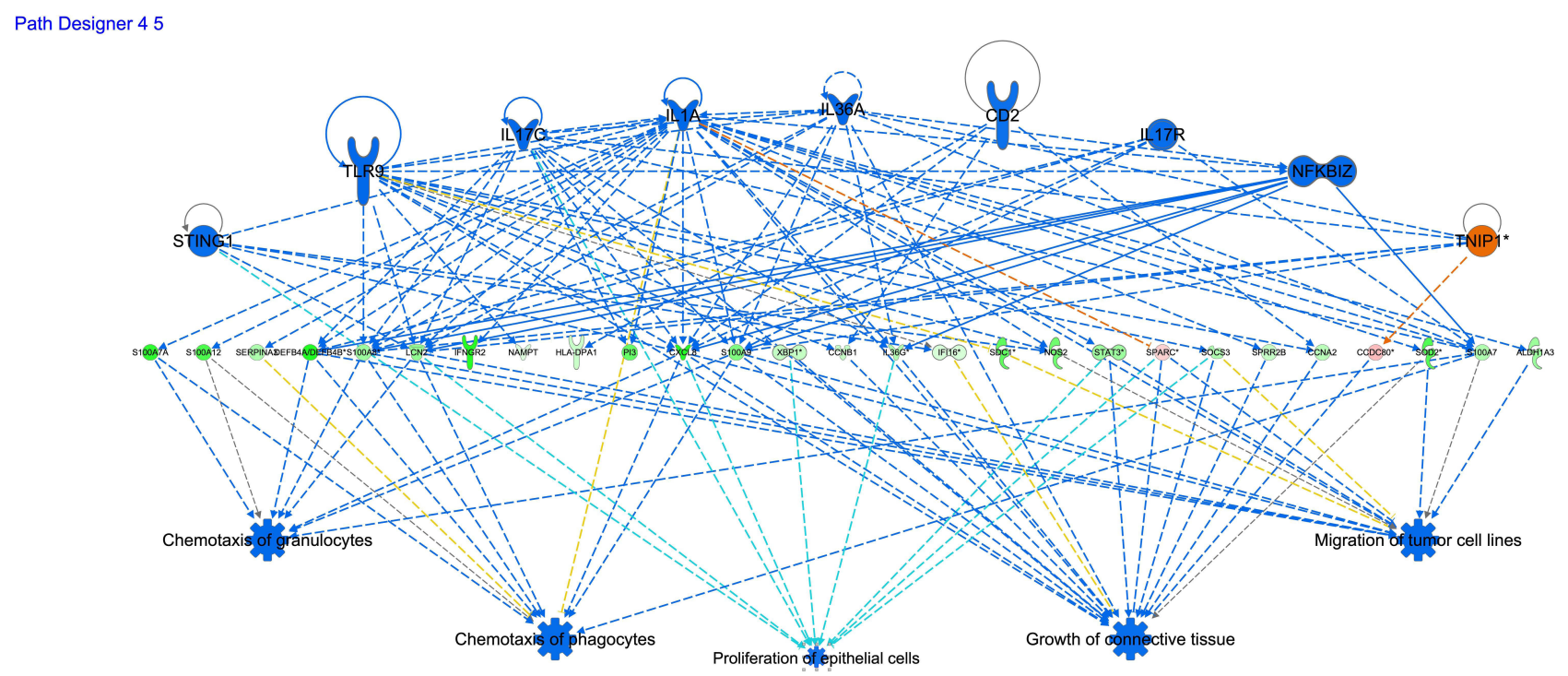

$\odot$ 2000-2021 QIAGEN. All rights reserved.

Figure 4 Regulatory effects analysis. The Regulatory effects network was generated by connections between predicted upstream regulators and DEGs and predicted downstream functions or diseases.

correlated with psoriasis severity. ${ }^{57-61}$ In addition, blockage of IL-21 could reduce the epidermal thickness and the expression of Th1 and Th17 genes. ${ }^{62}$

We showed that effective treatment with NB-UVB phototherapy in patients with psoriasis led to the downregulation of toll-like signaling pathways in lesional psoriasis. These are also responding with inhibited molecules of TLR in upstream regulator analysis by NB-UVB, particularly TLR3, TLR9, and TLR4. The effect of UV phototherapy can provide significant benefits for psoriatic treatment by blocking downstream pathways of TLR3 signaling and the function of TLR9. ${ }^{63,64}$ The downregulation of TLR9 following NB-UVB could affect the immunosuppressive state induced by the UV-induced ligands and downregulating pDCs. Additionally, inhibition of this signaling pathway could suppress immunological function and psoriatic lesion formation, including autoreactive $\mathrm{T}$ cells and other inflammatory cytokines. $^{64,65}$ Importantly, our results could emphasize that effect of NBUVB phototherapy can provide significant benefit in the treatment of psoriasis with inhibited downstream signaling pathways of TLR9, TLR3, TLR4. This major result may lead the way to a novel concept of psoriasis treatment. In addition, upstream regulators associated with transmembrane, including CD40 and CD2, were inhibited in responding to the anti-inflammation effect after phototherapy. CD40, expressed in keratinocytes involving signaling transduction activation, a proliferation of cytokine production, and activated $\mathrm{CD} 4+\mathrm{T}$ cells. ${ }^{66,67} \mathrm{CD} 2$, protein encoded within the psoriasis susceptibility region in the MHC, directly linked to disease susceptibility and Th1/ Th17 cells. ${ }^{68,69}$ It is conceivable that clinically effective NB-UVB therapy has an association with the downregulation of CD40 and CD2.

Limitations in the present study lie in the small sample size and the requirement of genetic confirmation in further studies. We decided to use the methodology of NGS and to complete the genome-wide coverage for transcriptome. We also conducted an advanced pathways analysis. Accordingly, we implemented the IPA to compensate for the limitations of our sample size. Importantly, our methodology and sample size calculation carefully followed the previous research of Krueger et al, as published in the Journal of Investigative Dermatology (JID) in 2012. We thus proceeded to investigate the transcriptional profiling and pathogenesis of psoriasis using RNA-seq. ${ }^{15}$ However, to the best of our knowledge, this is the first study that investigates the impact of phototherapy and provides a comprehensive gene expression profiling and molecular interaction network for lesional psoriasis with RNA-seq technique and advanced pathway analysis. Combining the molecular profiling of a clinical study with in-depth bioinformatics analysis could provide additional insights into the pathogenesis of psoriasis and mechanisms of 
phototherapy. Cutting-edge, systemic, and holistic disease understanding connecting the gaps between diagnostics and treatment, particularly phototherapy will emerge, decoding the immunopathogenesis behind psoriasis in the next future.

\section{Conclusion}

Our research provided the first comprehensive results of transcriptome with RNA sequencing and a bioinformatics analysis in NB-UVB phototherapy before and after psoriasis treatment. NB-UVB irradiation can inhibit the expression of the inflammatory signaling pathways, control the gene expression of inflammatory cytokines and increase the expression of anti-inflammatory signaling pathways. The use of NB-UVB phototherapy for its effect on the down-regulation of the toll-like signaling pathways was proposed for the treatment of lesional psoriasis. In addition, the effect of phototherapy on keratinocyte differentiation was emphasized in the resulting regulation of genes and inflammatory mediators that are related to cell proliferation and apoptosis. Our study illustrates how RNA-seq-based transcriptomics can shed light on the mechanism of phototherapy treatment at the molecular level. Ultimately, this research may increase our store of novel genetic knowledge and improve the care of patients with psoriasis.

\section{Acknowledgments}

This paper and the research behind it would not have been possible without the exceptional support from Asst Prof. Saranyoo Ponnikorn. The authors gratefully acknowledge the financial support provided by Thammasat University Research Fund under the TU Research Scholar, Contract No. 1/2560 and Chulabhorn International College of Medicine, Contract no T1/2563.

\section{Author Contributions}

All authors who have contributed to the data analysis, drafting or revising of this article have agreed on the selection of the journal to which this article will be submitted. They have furthermore given their final approval of the version to be published and have agreed to be accountable for all aspects of the work.

\section{Disclosure}

The authors state no conflicts of interest.

\section{References}

1. Chandran V, Raychaudhuri SP. Geoepidemiology and environmental factors of psoriasis and psoriatic arthritis. J Autoimmun. 2010;34(3): J314-J321. doi:10.1016/j.jaut.2009.12.001

2. Lowes MA, Bowcock AM, Krueger JG. Pathogenesis and therapy of psoriasis. Nature. 2007;445(7130):866. doi:10.1038/nature05663

3. Harden JL, Krueger JG, Bowcock AM. The immunogenetics of psoriasis: a comprehensive review. J Autoimmun. 2015;64:66-73. doi:10.1016/j.jaut.2015.07.008

4. Hemne P, Kunghatkar R, Dhoble S, Moharil S, Singh V. Phosphor for phototherapy: review on psoriasis. Luminescence. 2017;32 (3):260-270. doi:10.1002/bio.3266

5. Enk CD, Sredni D, Blauvelt A, Katz SI. Induction of IL-10 gene expression in human keratinocytes by UVB exposure in vivo and in vitro. J Immunol. 1995;154(9):4851-4856.

6. Coimbra S, Oliveira H, Reis F, et al. Interleukin (IL)-22, IL-17, IL23, IL-8, vascular endothelial growth factor and tumour necrosis factor- $\alpha$ levels in patients with psoriasis before, during and after psoralen-ultraviolet $\mathrm{A}$ and narrowband ultraviolet $\mathrm{B}$ therapy. $\mathrm{Br}$ $J \quad$ Dermatol. 2010;163(6):1282-1290. doi:10.1111/j.13652133.2010.09992.x

7. Weatherhead SC, Farr PM, Jamieson D, et al. Keratinocyte apoptosis in epidermal remodeling and clearance of psoriasis induced by UV radiation. J Investig Dermatol. 2011;131(9):1916-1926. doi:10.1038/ jid.2011.134

8. Zhang D, Chen Y, Chen L, et al. Ultraviolet irradiation promotes FOXP3 transcription via p53 in psoriasis. Exp Dermatol. 2016;25 (7):513-518. doi:10.1111/exd.12942

9. da Rosa JC, Kim J, Tian S, Tomalin LE, Krueger JG, Suárez-Fariñas M. Shrinking the psoriasis assessment gap: early gene-expression profiling accurately predicts response to long-term treatment. $J$ Investig Dermatol. 2017;137(2):305-312. doi:10.1016/j. jid.2016.09.015

10. Ungar B, Garcet S, Gonzalez J, et al. An integrated model of atopic dermatitis biomarkers highlights the systemic nature of the disease. $J$ Investig Dermatol. 2017;137(3):603-613. doi:10.1016/j. jid.2016.09.037

11. Zhang X-J, Huang W, Yang S, et al. Psoriasis genome-wide association study identifies susceptibility variants within LCE gene cluster at 1q21. Nat Genet. 2009;41(2):205. doi:10.1038/ng.310

12. Garber K. Psoriasis: From Bed to Bench and Back. Nature Publishing Group; 2011.

13. Roy PK, Datta A, Chatterjee AN. Saturation effects on immunopathogenic mechanism of psoriasis: a theoretical approach. Journal of Applied Functional Analysis. 2011;13(3):310-318.

14. Li B, Tsoi LC, Swindell WR, et al. Transcriptome analysis of psoriasis in a large case-control sample: RNA-seq provides insights into disease mechanisms. J Investig Dermatol. 2014;134(7):1828-1838. doi:10.1038/jid.2014.28

15. Jabbari A, Suárez-Fariñas M, Dewell S, Krueger JG. Transcriptional profiling of psoriasis using RNA-seq reveals previously unidentified differentially expressed genes. J Invest Dermatol. 2012;132(1):246. doi:10.1038/jid.2011.267

16. Meisgen F, Xu N, Wei T, et al. MiR-21 is up-regulated in psoriasis and suppresses T cell apoptosis. Exp Dermatol. 2012;21(4):312-314. doi:10.1111/j.1600-0625.2012.01462.x

17. Robinson MD, McCarthy DJ, Smyth GK. edgeR: a bioconductor package for differential expression analysis of digital gene expression data. Bioinformatics. 2010;26(1):139-140. doi:10.1093/bioinformatics/btp616

18. McCarthy DJ, Chen Y, Smyth GK. Differential expression analysis of multifactor RNA-Seq experiments with respect to biological variation. Nucleic Acids Res. 2012;40(10):4288-4297. doi:10.1093/ nar/gks042

19. NIH. Metascape. 2021. 
20. (LHRI) LoHRaI. The database for annotation, visualization and integrated discovery (DAVID). 2021.

21. QIAGEN US. Ingenuity pathway analysis software. 2021.

22. Krämer A, Green J, Pollard J, Tugendreich S. Causal analysis approaches in ingenuity pathway analysis. Bioinformatics. 2014;30 (4):523-530. doi:10.1093/bioinformatics/btt703

23. Johnson-Huang LM, Suárez-Farinas $M$, Sullivan-Whalen $M$, Gilleaudeau P, Krueger JG, Lowes MA. Effective narrow-band UVB radiation therapy suppresses the IL-23/IL-17 axis in normalized psoriasis plaques. J Investig Dermatol. 2010;130(11):2654-2663. doi:10.1038/jid.2010.166

24. Aydin B, Arga KY, Karadag AS. Omics-driven biomarkers of psoriasis: recent insights, current challenges, and future prospects. Clin Cosmet Investig Dermatol. 2020;13:611. doi:10.2147/CCID.S227896

25. Rácz E, Prens EP, Kurek D, et al. Effective treatment of psoriasis with narrow-band UVB phototherapy is linked to suppression of the IFN and Th17 pathways. J Investig Dermatol. 2011;131 (7):1547-1558. doi:10.1038/jid.2011.53

26. Bajaj S, Gautam R, Khurana A, Arora P, Sharma N. Effect of narrow band ultraviolet $\mathrm{B}$ phototherapy on $\mathrm{T}$ helper 17 cell specific cytokines (interleukins-17, 22 and 23) in psoriasis vulgaris. J Dermatol Treat. 2017;28(1):14-17. doi:10.1080/ 09546634.2016.1177162

27. Matos TR, Ling TC, Sheth V. Ultraviolet B radiation therapy for psoriasis: pursuing the optimal regime. Clin Dermatol. 2016;34 (5):587-593. doi:10.1016/j.clindermatol.2016.05.008

28. Yin L, Hu Y, Xu J, Guo J, Tu J, Yin Z. Ultraviolet B inhibits IL$17 \mathrm{~A} / \mathrm{TNF}-\alpha$-stimulated activation of human dermal fibroblasts by decreasing the expression of IL-17RA and IL-17RC on fibroblasts. Front Immunol. 2017;8:91. doi:10.3389/fimmu.2017. 00091

29. Hochberg M, Zeligson S, Amariglio N, Rechavi G, Ingber A, Enk C. Genomic-scale analysis of psoriatic skin reveals differentially expressed insulin-like growth factor-binding protein-7 after phototherapy. Br J Dermatol. 2007;156(2):289-300. doi:10.1111/j.13652133.2006.07628.x

30. Uzuncakmak TK, Karadag AS, Ozkanli S, et al. Alteration of tissue expression of human beta defensin-1 and human beta defensin-2 in psoriasis vulgaris following phototherapy. Biotech Histochem. 2020;95(4):243-248. doi:10.1080/10520295.2019.1673901

31. D'erme AM, Wilsmann-Theis D, Wagenpfeil J, et al. IL-36 $\gamma$ (IL-1F9) is a biomarker for psoriasis skin lesions. J Investig Dermatol. 2015;135(4):1025-1032. doi:10.1038/jid.2014.532

32. Swindell WR, Johnston A, Voorhees JJ, Elder JT, Gudjonsson JE. Dissecting the psoriasis transcriptome: inflammatory-and cytokine-driven gene expression in lesions from 163 patients. $B M C$ Genom. 2013;14(1):527. doi:10.1186/1471-2164-14-527

33. Keermann M, Kõks S, Reimann E, Prans E, Abram K, Kingo K. Transcriptional landscape of psoriasis identifies the involvement of IL36 and IL36RN. BMC Genom. 2015;16(1):1-11. doi:10.1186/s12864-0151508-2

34. Garlanda C, Dinarello CA, Mantovani A. The interleukin-1 family: back to the future. Immunity. 2013;39(6):1003-1018. doi:10.1016/j. immuni.2013.11.010

35. Hussain S, Berki DM, Choon S-E, et al. IL36RN mutations define a severe autoinflammatory phenotype of generalized pustular psoriasis. J Allergy Clin Immunol. 2015;135(4):1067-1070. e9. doi:10.1016/j.jaci.2014.09.043

36. Pietrzak AT, Zalewska A, Chodorowska G, et al. Cytokines and anticytokines in psoriasis. Clinica chimica acta. 2008;394(12):7-21. doi:10.1016/j.cca.2008.04.005

37. Takahashi H, Tsuji H, Hashimoto Y, Ishida-Yamamoto A, Iizuka H. Serum cytokines and growth factor levels in Japanese patients with psoriasis. Clin Exp Dermatol. 2010;35(6):645-649. doi:10.1111/ j.1365-2230.2009.03704.x
38. Cardoso PRG, de Andrade Lima EV, de Andrade Lima MM, et al. Clinical and cytokine profile evaluation in Northeast Brazilian psoriasis plaque-type patients. Eur Cytokine Netw. 2016;27(1):1-5. doi:10.1684/ecn.2016.0371

39. Piskin G, Koomen CW, Picavet D, Bos JD, Teunissen MB. Ultraviolet-B irradiation decreases IFN- $\gamma$ and increases IL-4 expression in psoriatic lesional skin in situ and in cultured dermal $\mathrm{T}$ cells derived from these lesions. Exp Dermatol. 2003;12(2):172-180. doi:10.1034/j.1600-0625.2003.120208.x

40. Piskin G, Sylva-Steenland RM, Bos JD, Teunissen MB. T cells in psoriatic lesional skin that survive conventional therapy with NBUVB radiation display reduced IFN- $\gamma$ expression. Arch Dermatol Res. 2004;295(12):509-516. doi:10.1007/s00403-004-0460-9

41. Piskin G, Tursen U, Sylva-Steenland R, Bos J, Teunissen M. Clinical improvement in chronic plaque-type psoriasis lesions after narrowband UVB therapy is accompanied by a decrease in the expression of IFN- $\gamma$ inducers-IL-12, IL-18 and IL-23. Exp Dermatol. 2004;13 (12):764-772. doi:10.1111/j.0906-6705.2004.00246.x

42. Platanias LC. Mechanisms of type-I-and type-II-interferon-mediated signalling. Nat Rev Immunol. 2005;5(5):375-386. doi:10.1038/nri1604

43. Kotenko SV, Gallagher G, Baurin VV, et al. IFN- $\lambda$ s mediate antiviral protection through a distinct class II cytokine receptor complex. Nat Immunol. 2003;4(1):69-77. doi:10.1038/ni875

44. Darnell JE, Kerr IM, Stark GR. Jak-STAT pathways and transcriptional activation in response to IFNs and other extracellular signaling proteins. Science. 1994;264(5164):1415-1421. doi:10.1126/ science. 8197455

45. Silvennoinen O, Ihle JN, Schlessinger J, Levy DE. Interferon-induced nuclear signalling by Jak protein tyrosine kinases. Nature. 1993;366 (6455):583-585. doi:10.1038/366583a0

46. Stark GR, Kerr IM, Williams BR, Silverman RH, Schreiber RD. How cells respond to interferons. Ann Rev Biochem. 1998;67(1):227-264. doi:10.1146/annurev.biochem.67.1.227

47. Chung JH, Youn SH, Koh WS, et al. Ultraviolet B irradiationenhanced interleukin (IL)-6 production and mRNA expression are mediated by IL-1 $\alpha$ in cultured human keratinocytes. $J$ Investig Dermatol. 1996;106(4):715-720. doi:10.1111/1523-1747.ep12345608

48. Valley QS. IL-6 signaling. 2021.

49. Kim AL, Labasi JM, Zhu Y, et al. Role of p38 MAPK in UVB-induced inflammatory responses in the skin of SKH-1 hairless mice. J Investig Dermatol. 2005;124(6):1318-1325. doi:10.1111/ j.0022-202X.2005.23747.x

50. Muthusamy V, Piva TJ. The UV response of the skin: a review of the MAPK, NF $\kappa \mathrm{B}$ and $\mathrm{TNF} \alpha$ signal transduction pathways. Arch Dermatol Res. 2010;302(1):5-17. doi:10.1007/s00403-0090994-y

51. Zhuang Y, Han C, Li B, et al. NB-UVB irradiation downregulates keratin-17 expression in keratinocytes by inhibiting the ERK1/2 and STAT3 signaling pathways. Arch Dermatol Res. 2018;310 (2):147-156. doi:10.1007/s00403-018-1812-1

52. Salvador JM, Brown-Clay JD, Fornace AJ. Gadd45 in stress signaling, cell cycle control, and apoptosis. Gadd45 Stress Sensor Genes. 2013;2013:1-19.

53. Maeda T, Hanna AN, Sim AB, Chua PP, Chong MT, Tron VA. GADD45 regulates $\mathrm{G} 2 / \mathrm{M}$ arrest, DNA repair, and cell death in keratinocytes following ultraviolet exposure. J Investig Dermatol. 2002;119(1):22-26. doi:10.1046/j.1523-1747.2002.01781.x

54. Takekawa M, Saito H. A family of stress-inducible GADD45-like proteins mediate activation of the stress-responsive MTK1/MEKK4 MAPKKK. Cell. 1998;95(4):521-530. doi:10.1016/S0092-8674(00) 81619-0

55. Emanuel P, Scheinfeld N. A review of DNA repair and possible DNA-repair adjuvants and selected natural anti-oxidants. Dermatol Online J. 2007;13(3). doi:10.5070/D39WW9F65D 
56. El-Abaseri TB, Hammiller B, Repertinger SK, Hansen LA. The epidermal growth factor receptor increases cytokine production and cutaneous inflammation in response to ultraviolet irradiation. Int Scholar Res Notices. 2013;2013:848705.

57. Boniface K, Guignouard E, Pedretti N, et al. A role for T cell-derived interleukin 22 in psoriatic skin inflammation. Clin Exp Immunol. 2007;150(3):407-415. doi:10.1111/j.1365-2249.2007.03511.x

58. Sa SM, Valdez PA, Wu J, et al. The effects of IL-20 subfamily cytokines on reconstituted human epidermis suggest potential roles in cutaneous innate defense and pathogenic adaptive immunity in psoriasis. J Immunol. 2007;178(4):2229-2240. doi:10.4049/ jimmunol.178.4.2229

59. Rutz S, Eidenschenk C, Ouyang W. IL-22, not simply a Th17 cytokine. Immunol Rev. 2013;252(1):116-132. doi:10.1111/imr.12027

60. Wolk K, Witte E, Wallace E, et al. IL-22 regulates the expression of genes responsible for antimicrobial defense, cellular differentiation, and mobility in keratinocytes: a potential role in psoriasis. Eur J Immunol. 2006;36(5):1309-1323. doi:10.1002/eji.200535503

61. Zheng Y, Danilenko DM, Valdez P, et al. Interleukin-22, a TH 17 cytokine, mediates IL-23-induced dermal inflammation and acanthosis. Nature. 2007;445(7128):648-651. doi:10.1038/ nature 05505

62. Botti E, Spallone G, Caruso R, Monteleone G, Chimenti S, Costanzo A. Psoriasis, from pathogenesis to therapeutic strategies: IL-21 as a novel potential therapeutic target. Curr Pharm Biotechnol. 2012;13(10):1861-1867. doi:10.2174/138920112802273281

63. Borkowski AW, Gallo RL. UVB radiation illuminates the role of TLR3 in the epidermis. $J$ Investig Dermatol. 2014;134 (9):2315-2320. doi:10.1038/jid.2014.167
64. Gao W, Xiong Y, Li Q, Yang H. Inhibition of toll-like receptor signaling as a promising therapy for inflammatory diseases: a journey from molecular to nano therapeutics. Front Physiol. 2017;8:508. doi:10.3389/fphys.2017.00508

65. Caramalho I, Lopes-Carvalho T, Ostler D, Zelenay S, Haury M, Demengeot J. Regulatory T cells selectively express toll-like receptors and are activated by lipopolysaccharide. J Exp Med. 2003;197 (4):403-411. doi:10.1084/jem.20021633

66. Karnell JL, Rieder SA, Ettinger R, Kolbeck R. Targeting the CD40-CD40L pathway in autoimmune diseases: humoral immunity and beyond. Adv Drug Deliv Rev. 2019;141:92-103. doi:10.1016/j. addr.2018.12.005

67. Noelle RJ, Roy M, Shepherd DM, Stamenkovic I, Ledbetter JA, Aruffo A. A 39-kDa protein on activated helper T cells binds CD40 and transduces the signal for cognate activation of B cells. Proc Natl Acad Sci. 1992;89(14):6550-6554. doi:10.1073/pnas.89.14.6550

68. Jenisch S, Koch S, Henseler T, et al. Corneodesmosin gene polymorphism demonstrates strong linkage disequilibrium with HLA and association with psoriasis vulgaris. Tissue Antigens. 1999;54 (5):439-449. doi:10.1034/j.1399-0039.1999.540501.x

69. Orlik C, Deibel D, Küblbeck J, et al. Keratinocytes costimulate naive human T cells via CD2: a potential target to prevent the development of proinflammatory Th1 cells in the skin. Cell Mol Immunol. 2020;17 (4):380-394. doi:10.1038/s41423-019-0261-x

\section{Publish your work in this journal}

Psoriasis: Targets and Therapy is international, peer-reviewed, open access journal focusing on psoriasis, nail psoriasis, psoriatic arthritis and related conditions, identification of therapeutic targets and the optimal use of integrated treatment interventions to achieve improved outcomes and quality of life. Visit http://www.dovepress. com/testimonials.php to read real quotes from published authors. 